MEDICAL ETHICS

\title{
Responsibility in health care: a liberal egalitarian approach
}

\section{A W Cappelen, O F Norheim}

\author{
See end of article for \\ authors' affiliations \\ .................. \\ Correspondence to: \\ Ole Frithjof Norheim, \\ Professor, Division for \\ Medical Ethics and the \\ Philosophy of Science, \\ Department of Public \\ Health and Primary Care, \\ University of Bergen \\ Kalfarveien 31, N-5018 \\ Bergen, Norway; \\ ole.norheim@isf.uib.no
}

Received 25 August 2004

Accepted for publication

14 October 2004
J Med Ethics 2005;31:476-480. doi: 10.1136/jme.2004.010421

Lifestyle diseases constitute an increasing proportion of health problems and this trend is likely to continue. A better understanding of the responsibility argument is important for the assessment of policies aimed at meeting this challenge. Holding individuals accountable for their choices in the context of health care is, however, controversial. There are powerful arguments both for and against such policies. In this article the main arguments for and the traditional arguments against the use of individual responsibility as a criterion for the distribution of scarce health resources will be briefly outlined. It is argued that one of the most prominent contemporary normative traditions, liberal egalitarianism, presents a way of holding individuals accountable for their choices that avoids most of the problems pointed out by the critics. The aim of the article is to propose a plausible interpretation of liberal egalitarianism with respect to responsibility and health care and assess it against reasonable counter-arguments.
P eople make different choices about how to live their lives. These choices also affect their health, the risks they face, and their need for medical treatment in the future. A key question is how considerations of individual responsibility should enter into the design of health care policies. Two issues are of particular importance in this context. First, if the same treatment is given to all patients the total cost of treatment will depend on how people behave. We then need to consider whether, and to what extent, the distribution of the costs of treatment should be related to a patient's behaviour. Secondly, in a situation where the budgets for health care are limited, it is necessary to ration treatment. Another important question is therefore whether the extent to which a disease is a result of individual choices should be allowed to affect the degree to which it is given priority.

Studies from WHO show that most of the leading risk factors contributing to the burden of disease in high income countries can be attributed to unhealthy life styles (table 1). WHO has also estimated that "in the developed countries of North America, Europe and the Asian Pacific, at least onethird of all disease burden is attributable to these five risk factors: tobacco, alcohol, blood pressure, cholesterol and obesity". ${ }^{1}$ The idea that individuals must take responsibility for their own health is also an increasingly focused topic in the popular press. Articles on health, fitness, and self-help seem to comprise an increasing proportion of consumer directed feature articles in newspapers.

Holding individuals accountable for their choices in the context of health care is, however, controversial. ${ }^{2-5}$ The aim of this article is to propose a plausible interpretation of liberal egalitarianism with respect to responsibility and health care, and assess it against reasonable counter-arguments.

\section{TWO TYPES OF ARGUMENT FOR THE IMPORTANCE OF RESPONSIBILITY IN HEALTH CARE}

What does it mean to hold somebody responsible in the context of health policy? We shall say that any health policy that links either the relative payment for treatment or the extent of treatment to factors that are under an individual's control holds that person responsible.
Generally there are two types of reason why we would want to link treatment or payment to individual behaviour. The first is backwards looking and related to the idea that the distribution of burdens and benefits should be linked to how different individuals contributed to the creation of these burdens and benefits. When applied to health policy this implies that, in order to determine how treatment or the cost of treatment should be distributed, we must ask how the need for treatment arose. More precisely it argues that the extent to which an individual contributed to the need for treatment might be a morally relevant factor. The basic intuition behind this view is that individuals are free to make certain choices about how to live their life and that they should be held responsible for such choices to the extent that they affect their need for treatment. For example, since smoking increases the risk for cancer and cardiovascular disease, people who freely decide to smoke should be held accountable for this choice.

The backward looking responsibility argument has been most important as a reason for not including certain types of treatment in public health care systems. Most people would, for example, agree that the cost of surgical removal of tattoos should be paid by the individual, not by the public. ${ }^{6}$ This intuition holds even if the subjective suffering is equal to that associated with disfiguring birthmarks, the removal of which is typically financed by the health service.

The second type of reason is consequentialist and forward looking. Consequentialist normative theories evaluate alternatives by comparing their consequences and the best alternative is simply the one that has the best consequences. Consequentialist arguments are not concerned with what individuals have done, but rather with how they will behave in the future. It links the distribution of costs or treatment to behaviour because it wants to affect future conduct in a certain way by creating incentives or disincentives to certain types of behaviour. Holding individuals responsible for their choices is seen simply as a means to an end.

Many prominent normative theories of distributive justice focus only on the second of these two reasons. For example, the quality of life years approach requires that limited resources are distributed between alternative treatments so as to maximise health outcomes in terms of quality adjusted 
Table 1 Leading 10 selected risk factors as percentage causes of disease burden in developed countries measured in disability adjusted life years (source: modified from World Health Organization, 2002')

\begin{tabular}{lc}
\hline Risk factor & $\begin{array}{c}\text { \% cause of disease } \\
\text { burden }\end{array}$ \\
\hline Tobacco & 12.2 \\
Blood pressure & 10.9 \\
Alcohol & 9.2 \\
Cholesterol & 7.6 \\
Overweight & 7.4 \\
Low fruit and vegetable intake & 3.9 \\
Physical inactivity & 3.3 \\
Illicit drugs & 1.8 \\
Unsafe sex & 0.8 \\
Iron deficiency & 0.7 \\
\hline
\end{tabular}

life years..$^{7-10}$ Such consequentialist theories are forward looking and exclude all types of backward looking considerations.

The arguments for health promotion in the literature are also based on forward looking or consequentialist normative theories, such as utilitarianism. The idea is that in order to promote health people must face the right incentives. ${ }^{11}$ Holding people responsible for their choices with respect to unhealthy life-styles could be justified purely by incentive arguments. Incentive mechanisms are often implemented at population level. Taxes and laws governing conduct can discourage people from smoking and excessive drinking. ${ }^{12}$ Governments or insurance plans could cover in full screening programmes such as mammography, smoking cessation programmes, and vaccinations, as well as testing and treatment for sexually transmitted diseases in order to encourage appropriate behaviour. ${ }^{11}$ Both negative and positive incentives can play a role in health promotion.

The disincentive argument has also been important in the design of effective treatment procedures. Many physicians, as well as national commissions on priorities, argue that patients should be held responsible for actions affecting the effectiveness of treatment. ${ }^{13-16}$ For example, continuous smoking will negatively affect the outcome of coronary bypass surgery as well as surgery for intermittent claudication. Continuous intravenous drug abuse could interfere with the effect of valve replacements because of re-infection. ${ }^{11}$ Excessive drinking reduces the chance of organ survival after liver transplantation. ${ }^{17}$ Consequently, many doctors argue that they are justified in requiring behavioural change if this is necessary for the treatment to be effective and that they should be allowed to refuse treatment if these requirements are not followed.

The implications of the forward looking and the backward looking perspectives often coincide. Clearly, one way of creating incentives is to link payment or treatment to past behaviour. However, even if the implications of the backward looking and the forward looking arguments sometimes coincide, this is far from always the case, and the difference in justification can hardly be exaggerated. This is easily seen by considering the situation in which there are no incentive effects-that is, where people's behaviour is unaffected by the incentive structure. In such a situation there is no forward looking reason for relating treatment or payment to past behaviour but a backward looking argument could still be relevant. To illustrate, consider a situation where smoking behaviour is unaffected by taxes on tobacco. In such a situation there would be no incentive reason for tobacco taxes, but it could still be argued that those who smoke should pay the expected cost of treatment.
Despite these powerful arguments, individual responsibility is, as we noted in the introduction, in general rejected as an important criterion in the distribution of resources in health care. ${ }^{2-4}$ We agree that there are forceful reasons why individual responsibility has been relegated to the background of political and theoretical arguments about distributive justice in health care. Below we consider two types of argument that justify this state of affairs.

\section{TWO TYPES OF ARGUMENT AGAINST INDIVIDUAL RESPONSIBILITY}

It is convenient to distinguish between normative and practical arguments against allowing individual responsibility for health to be an important factor in the distribution of health care. The latter are often as compelling as the former.

\section{Normative objections}

We shall distinguish between three different normative objections to holding individuals accountable. The first is what we will call the 'humanitarian objection'. According to this, we have an obligation to help people who are in real need, regardless of why they are in such a situation, provided that helping is possible and would not impose unacceptable sacrifices on those who provide the help. ${ }^{18}$ Consider a man who is a long-term smoker who at age 60 develops coronary heart disease. He now suffers from angina pectoris and is at risk for myocardial infarction, or a stroke. The cardiologist makes further diagnostic tests and tells him he needs a percutaneous coronary intervention. Many think it would be a harsh judgement to deny him the procedure because the disease could be said to be self-inflicted. The humanitarian concern would be even stronger if we assume that the patient has already suffered a myocardial infarction, is in a great deal of pain and at high risk of dying. Should treatment be denied him? Many would strongly object to this.

The 'liberal objection' is concerned with the collateral effects of denying a person treatment. Even if we could accept inequality in health, there are other types of inequality-for example, political inequality, which we would not accept. Some theorists within the liberal egalitarian tradition argue that giving weight to individual responsibility in the context of health care would violate the liberal principle of equal political and civil rights because persons cannot exercise these rights if their health condition is sufficiently bad (for a more sophisticated version of this argument see reference 3). Haavi Morreim suggests that exclusion, or disenrolment, from health insurance plans could be a likely consequence of implementing responsibility. ${ }^{11}$ Such a result would be even worse than denial of treatment for a single condition, and would further undermine people's opportunity to exercise their political and civil rights.

Perhaps the most fundamental normative objection is what we could call the 'fairness objection'. This focuses on the fact that the actual consequences of a choice partly depend on factors outside the individual's control. Those who make the same choices may not have the same need for treatment. This could partly be due to different degrees of luck (for example, that the parachute did not open), or different genetic dispositions (for example, a disposition to develop cancer or cardiovascular diseases). ${ }^{19}$ If people are forced to pay for their own treatment when the need for it can be said to be selfinflicted, then we are holding individuals responsible for too much.

\section{Practical objections}

The second type of objection holds that, even though individual responsibility for health may be important in principle, introducing such considerations into actual policy is difficult and will create new problems. 
The 'informational objection' is concerned with two types of problem. The first is related to asymmetric information about a patient's past behaviour. Typically, the patient knows far more about his or her own past behaviour than the doctor. If this asymmetry is to be corrected there is a danger of jeopardising the physician-patient relationship. The physician providing treatment is the most likely person to enforce the necessary measures for holding patients responsible for the consequences of their actions and to gather information about their past behaviour. For example, denial of care based on this rationale can seriously undermine the physician's identity as caregiver and thus the physician-patient relationship itself. Moreover, the physician being assigned a controlling role might easily intrude on patients' privacy. A second informational problem is related to the fact that information about the relationship between behaviour and the need for treatment is often uncertain, even when information about patients' past behaviour is readily available. Although much is known about the relationship between unhealthy life-styles and disease, this is strongly mediated by genetic and environmental factors. Establishing a causal relationship between behaviour and outcomes is difficult for most conditions and it is hard to establish with certainty that a particular type of behaviour is the sole cause of the disease in question. ${ }^{14}$

The objection of "non-neutrality" is concerned with the possibility that only certain types of risky behaviour will be identified as of special concern. What kind of risky behaviour should be identified as of special concern? Why should smokers be "punished" while those who eat too much or exercise too little are not? One such important worry is the possibility of opening up for "moralism" ${ }^{20}$ How do we draw the line between "justified" inequalities and "moralistic" judgements about a person's choice or character? A liberal state should be neutral to the ways of life people choose. Identification of those types of behaviour for which people should be held responsible should be determined by the impact on health, but considering the high emotions aroused when tobacco, alcohol, and unsafe sex are debated, there is reason to fear that in practice it is difficult to draw this line.

\section{A LIBERAL EGALITARIAN RESPONSE: HOLDING INDIVIDUALS RESPONSIBLE FOR THEIR CHOICE, NOT FOR THE CONSEQUENCES OF THEIR CHOICE}

The arguments outlined above are compelling. However, most of them are aimed at what we believe is a wrong interpretation of what it means to hold people responsible for their choices, namely the view that it implies they should be held accountable for the actual consequences of their choices. Liberal egalitarian theories suggest an alternative interpretation of what it means to hold a person responsible that avoids most of the objections presented above. In order to show this, we give a brief presentation of the main features of liberal egalitarian theories of justice.

The revival of liberal egalitarian theories of justice, and the focus on responsibility in contemporary normative theory, can be traced back to the seminal work by John Rawls. ${ }^{21}$ As noted by Thomas Nagel:

[W] hat Rawls has done is to combine the very strong principles of social and economic equality associated with European socialism with the equally strong principles of pluralistic toleration and personal freedom associated with American liberalism, and he has done so in a theory that traces them to a common foundation. The result is closer in spirit to European social democracy than to any mainstream American political movement. ${ }^{22}$
The link between freedom and individual responsibility has evolved as a central topic in contemporary political theory. Rawls' early contribution-as a critique of what Amartya Sen later labelled welfarism-was to introduce individual responsibility, but only for preferences. Dworkin deepens the critique of welfarism and develops the theory of equality of resources. People are to be held responsible for their ambitions, but not the resources they receive in the social and natural "lottery". ${ }^{23}$ Inequalities arising from brute luck in the social and natural lottery should be compensated. If resources are distributed equally, what people do with their resources is irrelevant for a theory of equality. Sen, in his way, ${ }^{24}$ and Roemer, ${ }^{25}{ }^{26}$ Cohen, ${ }^{27}$ and Arneson ${ }^{28}$ have developed fine-tuned versions of the equal opportunity principle where the equalisandum is defined as capabilities, advantage, opportunity for welfare, etc.

Liberal egalitarian theories of distributive justice argue that a central goal of public policy should be to secure equal opportunities for all individuals. All equal opportunity approaches argue that society should eliminate inequalities that arise from some, but not all, factors. However, different versions of this approach disagree about which factors are legitimate sources of inequality and which are not. One prominent position argues that equal opportunity requires that all inequalities that arise from factors outside the agent's control in the social and the natural lottery, such as a person's natural and genetic abilities, should be eliminated, but that inequalities or costs that arise from factors under the agent's control should be accepted. ${ }^{19}$ Cohen refers to the factors outside the agent's control as "circumstances" and the factors that are within the person's control as "choice" ${ }^{27}$ A liberal egalitarian approach can then be seen as consisting of two parts. First, the liberal principle that people should be held accountable for their choices, what we may call the principle of responsibility, and secondly the egalitarian principle that individuals who make the same choices should also have the same outcomes, what we may call the "principle of equalisation". Applied to the context of health care the principle of equalisation implies that all individuals who make the same choices should be treated as if they were identical with respect to all factors outside their own control-that is, as if they had the same disposition to become sick and faced the same health risks.

It is important to distinguish the liberal egalitarian theory from the liberalist theory. Both are concerned with the equalisation of opportunities, but while liberal egalitarian theories want to eliminate the effect of all factors outside individuals' control, the liberalists are primarily concerned with non-discrimination. Liberals who argue for equal opportunities are mostly concerned about eliminating formal and informal barriers. They are not supporting a substantial positive commitment to securing equal opportunities ("levelling the playing field"). In other words, the liberal argument is more focused on responsibility and only formally interested in equality. ${ }^{19}$

Having said this, we are now in a position to state a common misunderstanding of liberal egalitarianism. The most important misinterpretation is that these theories argue that individuals should be held responsible for the consequences of their choice. In the context of health care this would imply that individuals should be refused treatment (or collectively financed treatment) if they could have avoided the need for treatment by making different choices. However, the principle of responsibility states that individuals should be held responsible for their choices, not for the consequences of their choices. It is only in the special case where the outcome depends solely on the individual's choices and not on any other factors that this principle implies that 
individuals should be held responsible for the consequences of their actions. To hold people responsible for the actual consequences of their choice would therefore be to hold them responsible for too much. Some people are lucky and some are unlucky when they engage in risky behaviour. It would be unfair to hold people responsible for differences in luck. Ideally we would therefore want to reward or tax the behaviour as such rather than the consequences of the action. This means that the correct place to introduce responsibility is not at the sick bed or beside the road accident victim.

This interpretation suggests ways in which individual responsibility can be introduced in health care without falling victim to the objections discussed above. Below we present one way of doing this, by levying taxes on certain types of behaviour, and argue that this way of holding individuals responsible would avoid most of the objections presented above.

\section{HOLDING PEOPLE RESPONSIBLE FOR THEIR CHOICES THROUGH TAXES}

To see the implications of this view it is useful to take an example. Consider a situation in which physicians and the health care system treat all individuals as equals, regardless of the choices they have made. That is, everyone is given the best available treatment. The question then becomes how we should distribute the costs of treatment between individuals in the economy. Assume furthermore that the need for treatment of a particular disease is proportionally related to the consumption of a particular good (for example, tobacco) and that this good can be taxed. In this situation the implication of the liberal egalitarian theory is straightforward. This theory would, in the absence of an efficient insurance market, want to tax tobacco in order to finance the costs of treatment rather than to require that patients pay for their own treatment. The theory does not determine uniquely how the level of taxes should be decided, but one plausible alternative would be to set the per-unit taxes on tobacco so that the total tax revenues are equal to the additional cost of treatment associated with smoking. Another implication of the theory is that all smokers should pay the same tax rate independent of their genetic disposition and the expected cost of their treatment. To do otherwise would violate the principle that all individuals who make the same choice should also face the same costs.

Let us now examine how this way of introducing individual responsibility avoids the objections discussed above. The first point to note is that holding people responsible for choices through taxes will not violate humanitarian concerns. No patients would be denied diagnostics or treatment because of their choices. Of course the tax burden imposed on each person ex ante (at the point of choice) could be considered as inhumanitarian if it imposes an extremely high tax. However, the range of taxes implemented in most cases would probably not invoke such an objection. Secondly, this policy would avoid the liberal objection since everyone who becomes sick is treated and taxes on tobacco will not, unless excessively high, restrict the set of health related opportunities. Rather, it secures that other people's opportunity sets remain unrestricted by the smokers' choice.

Most importantly, the liberal egalitarian theory avoids the fairness objection since the whole point of the tax is to eliminate the effect of factors outside the control of the agent. Individuals with different luck or with a different disposition to become sick are given the same treatment and face the same taxes. The fairness objection is directed against the liberalist interpretation of responsibility that holds individuals responsible for the actual consequences of their choices.

The tax policy also avoids objections based on practicability. Tax policies will not, and this is important, undermine the physician-patient relationship. Physicians are not assigned the role of holding people responsible for their choices. Many (but not all) choices regarding life-style involve "consumption" of various types of goods, such as cigarettes, alcohol, food (including salt), organised sport, or exercise, etc. Taxes or tax deductions can easily be attached to the consumption of these goods and need not involve any active role for physicians or providers.

Furthermore, the rejection of responsibility based on the argument that we do not know whether there is a direct connection between a patient's condition and his or her choice of life-style does not undermine the liberal egalitarian approach. Holding people responsible for their choices is justified if one can demonstrate that a particular choice is likely to impose a higher risk on that person when compared with another person who is equal in all other relevant aspects.

The use of the tax mechanism would not eliminate the problem of non-neutrality. It will still be possible to use the responsibility argument as a way of introducing "moralistic" judgement. However, it is likely to reduce this problem because tax policies will typically be decided through democratic procedures and not by individuals in the health care system.

\section{DISCUSSION}

Even if we believe that the liberal egalitarian response answers many of the objections, there are still problems with this approach. A fundamental-and remaining-issue is the informational problem of drawing the precise cut between those factors that are under a person's control and those that are outside it. New genetic knowledge might clarify which risk factors are attributable to choice and which are not. We therefore believe that as we obtain more genetic information on susceptibility, the understanding of individual responsibility within liberal egalitarianism could become increasingly more important.

Moreover, people have different probabilities of becoming a smoker or an alcoholic depending on family background, social class, etc. It is well documented that not only is unhealthy behaviour statistically more likely among people who are poor, but also that people with lower socioeconomic status on average have inferior health. This suggests that it can be misleading to view unhealthy behaviour as freely chosen (see Roemer for a good discussion on this point ${ }^{26}$ ).

Another unresolved issue is that not all types of behaviour can be associated with a taxable product. It is relatively easy to levy taxes on consumer goods, but how should we tax choices such as exercising too little or having unsafe sex? Although it is possible to assign tax exemptions to membership of fitness clubs, on condoms etc., we acknowledge the problem that not all unhealthy life-style choices can be handled in the same way.

In this article we have focused on the liberal egalitarian argument for holding individuals responsible for their choices. This must, of course, be combined with the incentive argument. We have ignored the incentive argument in most of our discussion in order to focus on the backward looking arguments for holding individuals responsible. Even if people's behaviour is totally unaffected by the existence of taxes, in which case there is no incentive argument for taxes, we still contend that justice requires that smokers or others who make risky choices should contribute more to the financing of health care. 


\section{Authors' affiliations}

A W Cappelen, Department of Economics, University of Oslo and the Norwegian School of Economics, Norway

O F Norheim, Division for Medical Ethics and the Philosophy of Science, Department of Public Health and Primary Care, University of Bergen, Norway

Competing interests: none declared

\section{REFERENCES}

1 World Health Organization. The world health report: reducing risks, promoting healthy life. Geneva: WHO, 2002.

2 Wikler D. Persuasion and coercion for health: ethical issues in governmental efforts to change lifestyles. Milbank Memorial Fund Q 1978;56:303-38.

3 Daniels N. Democratic equality: Rawls's complex egalitarianism. In:

Freeman S, ed. The Cambridge companion to Rawls. Cambridge: Cambridge University Press, 2003:241-76.

4 Harris J. Could we hold people responsible for their own adverse health? J Contemp Health Law Policy 1995; 12:147-53.

5 Wikler D. Personal and social responsibility for health. In: Anand S, Peter F, Sen A eds. Public health ethics, and equity. Oxford: Oxford University Press, 2004:109-34

6 Klein R, Day P, Redmayne S. Managing scarcity. Priority setting and rationing in the National Health Service. Buckingham: Open University Press, 1996.

7 Williams A. Economics of coronary artery bypass grafting. BMJ 1985;291:326-9.

8 Williams A. QALYS and ethics: a health economist's perspective. Soc Sci Med 1996;43:1795-804

9 Drummond M, Stoddart G, Torrance G. Methods for the economic evaluation of health care programmes. Oxford: Oxford University Press, 1997.

10 Menzel PT. Strong medicine. The ethical rationing of medical care. New York: Oxford University Press, 1990

11 Haavi Morreim E. Sticks and carrots and baseball bats: economic and other incentives to modify health behaviour. In: Callahan D, ed. Promoting healthy behaviour. How much freedom? Whose responsibility? Washington DC: Georgetown University Press, 2000:56-75.
12 LeGrand J. Equity and choice. An essay in economics and applied philosophy. London: Harper Collins Academic, 1991.

13 Norges Offentlige Utredninger. Prioritering på ny. Gjennomgang av retningslinjer for prioriteringer innen norsk helsetjeneste. Oslo: Statens forvaltningstjeneste; Statens trykking, 1997;18 [in Norwegian].

14 Norges Offentlige Utredninger. Retningslinjer for prioritering innen den norske helsetjenesten. Oslo: Universitetsforlaget, 1987;23 [in Norwegian].

15 Ministry of Health. Choices in health care. A report by the Government Committee on Choices in Health Care. The Hague: Ministry of Welfare, Health and Cultural Affairs, 1992.

16 Vårdens svåra val. Rapport från utredningen om prioriteringear innom hälsoog sjukvården. Stockholm: Statens offentliga utredningar, 1993 [in Swedish]).

17 Delmonico FL, Jenkins RL, Freeman R, et al. The high-risk liver allograft recipient. Should allocation policy consider outcome? Arch Surg 1992;127:579-84.

18 Scanlon T. The diversity of objections to inequality. In: Clayton M, Williams A eds. The ideal of equality. New York: Palgrave, Macmillan 2002:41-59.

19 Buchanan A, Brock D, Daniels N, et al. From chance to choice. Genetics and justice. Cambridge, MA: Oxford University Press, 2002

20 Minkler M. Personal responsibility for health: context and controversies. In: Callahan D, ed. Promoting healthy behaviour. How much freedom? Whose responsibility? Washington DC: Georgetown University Press, 2000:1-22.

21 Rawls J. A theory of justice. Cambridge, MA: Belknap Press of Harvard University Press, 1971

22 Nagel T. Concealment and exposure and other essays. Cambridge, MA: Oxford University Press, 2002.

23 Dworkin R. What is equality? Part 2: Equality of resources. Philosophy and Public Affairs 1981;10:283-345.

24 Sen AK. Inequality reexamined. Oxford: Clarendon Press, 1992.

25 Roemer J. A pragmatic theory of responsibility for the egalitarian planner. Philosophy and Public Affairs 1993;22:146-66.

26 Roemer J. Equality of opportunity. Cambridge, MA: Harvard University Press, 1998.

27 Cohen GA. On the currency of egalitarian justice. Ethics 1989;99:906-44.

28 Arneson R. Equality and equal opportunity for welfare. Philosophical Studies 1989;56:159-94.

\section{bmjupdates+}

bmjupdates+ is a unique and free alerting service, designed to keep you up to date with the medical literature that is truly important to your practice.

bmjupdates+ will alert you to important new research and will provide you with the best new evidence concerning important advances in health care, tailored to your medical interests and time demands.

Where does the information come from?

bmjupdates+ applies an expert critical appraisal filter to over 100 top medical journals A panel of over 2000 physicians find the few 'must read' studies for each area of clinical interest

Sign up to receive your tailored email alerts, searching access and more...

www.bmjupdates.com 